\title{
KNOWLEDGE, ATTITUDES, AND PRACTICES TOWARDS THE INFLUENZA VACCINE AMONG ADULT POPULATION IN PLOVDIV, BULGARIA
}

\author{
Vanya RANGELOVA ${ }^{1 凶}$, Ani KEVORKYAN ${ }^{1}$, Ralitsa RAYCHEVA ${ }^{2}$, Diruchi AMUDZHIYAN ${ }^{3}$, \\ Mariana ALEKSANDROVA ${ }^{4}$, Sara SARIYAN ${ }^{5}$
}

${ }^{1}$ Department of Epidemiology and Disaster Medicine, Faculty of Public Health, Medical University of Plovdiv, Bulgaria

${ }^{2}$ Department of Social Medicine and Public Health, Faculty of Public Health, Medical University of Plovdiv, Plovdiv, Bulgaria

${ }^{3}$ Department of Midwifery Cares, Faculty of Public Health, Medical University of Plovdiv, Plovdiv, Bulgaria

${ }^{4}$ Medical College, Medical University of Plovdiv, Plovdiv, Bulgaria

${ }^{5} 4$ th year Medical student, Medical Faculty, Medical University of Plovdiv, Plovdiv, Bulgaria

Received 21 July 2021, Accepted 17 Aug 2021

https://doi.org/10.31688/ABMU.2021.56.3.06

\section{Abstract}

Introduction. Vaccination is the most effective and safest means of preventing influenza infection. The coverage with influenza vaccine is not satisfactory across Europe and one of the main obstacles is vaccine hesitancy.

The objective of the study was to assess the knowledge, attitudes, and practices of the population towards the seasonal influenza vaccine.

Materials and methods. Between November 2016 - February 2017 a cross-sectional study using a semi-structured questionnaire was conducted in Plovdiv (Bulgaria), covering 545 people over 18 years old. Standard descriptive statistics was used to summarize demographic characteristics. Differences between observed and theoretical distributions were tested using chi-square test for independence. A 2-sided p-value of $<0.05$ was considered statistically significant.

\section{Résumé}

Connaissances, attitudes et pratiques envers le vaccin contre la grippe chez la population adulte de Plovdiv, Bulgarie

Introduction. La vaccination est le moyen le plus efficace et le plus sûr de prévenir l'infection grippale. La couverture vaccinale avec le vaccin antigrippal n'est pas satisfaisante dans toute l'Europe et l'un des principaux obstacles est la réticence à la vaccination.

L'objectif de l'étude était d'évaluer les connaissances, les attitudes et les pratiques du public envers le vaccin contre la grippe saisonnière.

Matériels et méthodes. Entre novembre 2016 et février 2017, une étude transversale utilisant un questionnaire semi-structuré a été menée en Plovdiv (Bulgarie), couvrant 545 personnes de plus de 18 ans. Des statistiques descriptives standard ont été utilisées 
Results. The vaccine uptake was $11 \%$. An association was found between the age of the respondents and administration of the vaccine $\left(\chi^{2}=16.687 \mathrm{p}=0.005\right)$, vaccination status and educational level $\left(\chi^{2}=27.002\right.$, $\mathrm{p}=0.00002) .27 .6 \%$ of the unvaccinated respondents were uncertain about the effectiveness of the vaccine and $26.8 \%$ had the perception this is not a serious disease. More than half of the respondents (51.1\%) were willing to change their attitude towards the influenza vaccination, the recommendation from a doctor being the most important (40.8\%).

Conclusions. Seasonal influenza vaccine uptake was low in our study and the main drivers for vaccine hesitancy were concerns regarding its safety and effectivenes. Recommendation of the vaccine from a general physician was the most important source for influencing the attitudes towards the vaccine. This highlights the importance of general physicians' involvement and the need to spread public awareness regarding the efficacy and benefits of seasonal influenza vaccination.

Keywords: influenza, vaccination, attitudes, knowledge, practices, hesitancy.

\section{INTRODUCTION}

Seasonal influenza is an acute respiratory infection caused by influenza viruses that affects all age groups and is one of the most widespread communicable diseases worldwide ${ }^{1}$. According to World Health Organization's global estimates, $5-10 \%$ of adults and $20-30 \%$ of children have influenza annually ${ }^{2}$. In moderate climates, influenza seasonal epidemics occur during the winter season, while in tropical areas, influenza epidemics might occur throughout the year ${ }^{1,3}$.

Vaccination is the most effective and safest means of preventing influenza infection. Currently licensed influenza vaccines are safe and efficacious and prevent significant annual morbidity and mortality ${ }^{4}$. The latest recommendations of the World Health Organization and the U.S. Center for Disease Control and Prevention state that individuals aged 6 months and older must be encouraged to get vaccinated against influenza in an attempt to expand protection to more people. It is particularly important for individuals in high-risk groups to receive the annual influenza vaccine, to prevent the risk of serious complications ${ }^{5,6}$. pour résumer les caractéristiques démographiques. Les différences entre les distributions observées et théoriques ont été testées à l'aide d'un test d'indépendance du chi carré. Une valeur p bilatérale $<0,05$ a été considérée comme statistiquement significative.

Résultats. Le taux de vaccination était de $11 \%$. Une association a été trouvée entre l'âge des répondants et l'administration du vaccin $(\chi 2=16.687 \mathrm{p}=0.005)$, le statut vaccinal et le niveau d'éducation $(\chi 2=27.002$, $\mathrm{p}=0.00002) .27,6 \%$ des répondants non vaccinés n'étaient pas certains de l'efficacité du vaccin et $26,8 \%$ avaient l'impression qu'il ne s'agissait pas d'une maladie grave. Plus de la moitié des personnes interrogées $(51,1 \%)$ étaient prêtes à changer d'attitude vis-à-vis de la vaccination contre la grippe et la recommandation et les conseils d'un médecin étaient les plus importants (40,8\%).

Conclusions. L'absorption du vaccin contre la grippe saisonnière était faible dans notre étude et le principal facteur d'hésitation à la vaccination était les inquiétudes concernant l'innocuité et l'efficacité du vaccin. Dans le même temps, la recommandation du vaccin par un médecin généraliste était la source la plus importante pour influencer les attitudes envers vaccination.

Mots-clés: grippe, vaccination, attitudes, connaissances, pratiques, hésitations.

The long-standing system of epidemiological surveillance of influenza in Bulgaria shows that the annual influenza epidemics are a serious health and financial problem for our country. In the district cities alone, an average of about 1,400,000 to $1,600,000$ cases of acute respiratory illness and influenza occur each year and they account for $10-30 \%$ of the cases of temporary disability. At the same time, in Bulgaria the immunization coverage with influenza vaccines is very low, constantly.

The vaccine coverage with influenza vaccine is not satisfactory in most of the countries across Europe and one of the main obstacles in front of a successful vaccination campaign is vaccine hesitancy. Even in the light of the recent coronavirus disease 2019 (COVID-19) pandemic, many remain skeptical and intend to abstain from voluntary vaccinations based upon myths, misinformation, and/ or safety concerns ${ }^{8-12}$. Known predictors of vaccination have been described in the literature, including receiving a doctor's recommendation for vaccination, and positive beliefs about vaccine safety and effectiveness ${ }^{13-15}$. However, little is known about attitudes and practices regarding influenza vaccination in Bulgaria. Exploring and understanding the 
different sociodemographic and medical factors that may hinder the voluntary vaccination against the seasonal influenza is crucial to formulate an effective national policy aimed at improving the vaccination rate against epidemic, as well as other epidemics and pandemics such as COVID-19.

The OBJective OF THE STUDY was to assess the knowledge, attitudes, and practices of the public towards the seasonal influenza vaccine and their possible association with the participant's influenza vaccination history.

\section{Materials AND MEthods}

In the period November 2016 - February 2017, a cross-sectional study using a semi-structured questionnaire was conducted in the city of Plovdiv (Bulgaria), covering 545 people over 18 years old. Plovdiv is the second largest city in Bulgaria and the total population of the region at the end of 2016 was estimated to be 671,573 people $^{16}$. The survey included 15 questions, 6 of which with more than one possible answer. The questions were divided into three panels: demographic data - 4 questions, assessment of the knowledge about flu as an infection - 5 questions, and the attitudes for influenza immunization - 6 questions. Three different approaches were used to gather information: visits to outpatient clinics $(n=147)$, reaching medical university students $(\mathrm{n}=166)$ and online surveys $(n=232)$. An anonymous survey was generated through the web-based platform provided by Google Forms. Standard descriptive statistics was used to summarize demographic characteristics. Qualitative variables are presented as numbers/totals and percentages (n, \%). Differences between observed and theoretical distributions were tested using chi-square test for independence. A two-sided p-value of $<0.05$ was considered statistically significant. Statistical analyses were performed using SPSS Statistics v. 26 software (IBM Corp., Chicago, IL, USA).

The study received an ethical exemption from Ethics Committee as it met one of the criteria for exemption (an anonymous survey or interview that do not involve collection of identifiable data).

\section{Results \\ Demographics}

A total of 545 people took part in the survey. The demographic characteristics of the respondents depending on their vaccination status are presented in Table 1. The largest share in both groups (vaccinated vs. unvaccinated) were the participants aged between $18-24$ years and $25-34$ years $(25.0 \%$ vs. $35.3 \%$, and $23.3 \%$ vs. $31.3 \%$ respectively). Considering the area of residency, $71.7 \%$ of the vaccinated and $76.3 \%$ of the unvaccinated respondents were from the

Table 1. Socio-demographic characteristics of the respondents

\begin{tabular}{|c|c|c|c|}
\hline Characteristics & $\begin{array}{c}\text { Vaccinated respond- } \\
\text { ents } \\
(n=60)\end{array}$ & $\begin{array}{c}\text { Unvaccinated respond- } \\
\text { ents } \\
(n=485)\end{array}$ & p-value \\
\hline $\begin{array}{l}\text { Age group } \\
18-24 \text { years } \\
25-34 \text { years } \\
35-44 \text { years } \\
45-54 \text { years } \\
55-64 \text { years } \\
\geq 65 \text { years }\end{array}$ & $\begin{array}{c}15(25.0 \%) \\
14(23.3 \%) \\
9(15 \%) \\
4(6.7 \%) \\
10(16.7 \%) \\
8(13.3 \%)\end{array}$ & $\begin{array}{l}171(35.3 \%) \\
152(31.3 \%) \\
70(14.5 \%) \\
35(7.2 \%) \\
35(7.2 \%) \\
22(4.5 \%)\end{array}$ & 0.005 \\
\hline $\begin{array}{l}\text { Area of residency } \\
\text { Plovdiv region } \\
\text { Smaller regional city } \\
\text { Village } \\
\text { No answer }\end{array}$ & $\begin{array}{l}43(71.7 \%) \\
12(20 \%) \\
4(6.7 \%) \\
1(1.6 \%)\end{array}$ & $\begin{array}{c}370(76.3 \%) \\
70(14.5 \%) \\
37(7.6 \%) \\
8(1.6 \%)\end{array}$ & 0.518 \\
\hline $\begin{array}{c}\text { Education level } \\
\text { No education } \\
\text { Below high school } \\
\text { High school } \\
\text { University degree } \\
\text { No answer }\end{array}$ & $\begin{array}{c}0 \\
4(6.7 \%) \\
19(31.7 \%) \\
35(58.3) \\
2(3.3 \%) \\
\end{array}$ & $\begin{array}{c}1(0.2 \%) \\
4(0.8 \%) \\
211(43.5 \%) \\
253(52.2 \%) \\
16(3.3 \%) \\
\end{array}$ & 0.000 \\
\hline $\begin{array}{c}\text { Financial situation } \\
\text { Difficult } \\
\text { Manageable } \\
\text { Comfortable } \\
\text { No answer }\end{array}$ & $\begin{array}{c}17(28.3 \%) \\
26(43.3 \%) \\
11(18.3 \%) \\
6(10.1 \%)\end{array}$ & $\begin{array}{c}130(26.8 \%) \\
200(41.2 \%) \\
134(27.6 \%) \\
21(4.4 \%)\end{array}$ & 0.565 \\
\hline
\end{tabular}


Table 2. Knowledge about influenza among the respondents $(n=545)$

\begin{tabular}{|c|c|c|}
\hline Characteristics & Frequency (n) & $\%$ \\
\hline $\begin{array}{l}\text { The flu is a contagious disease } \\
\text { True } \\
\text { False } \\
\text { Do not know } \\
\text { No answer }\end{array}$ & $\begin{array}{c}523 \\
9 \\
12 \\
1\end{array}$ & $\begin{array}{c}96.0 \\
1.6 \\
2.2 \\
0.2\end{array}$ \\
\hline $\begin{array}{l}\text { Influenza infection can lead to serious complications } \\
\qquad \text { True } \\
\text { False } \\
\text { Do not know } \\
\text { No answer }\end{array}$ & $\begin{array}{c}524 \\
5 \\
13 \\
3 \\
\end{array}$ & $\begin{array}{c}96.1 \\
0.9 \\
2.4 \\
0.6\end{array}$ \\
\hline $\begin{array}{l}\text { In children and the elderly there is a higher risk for severe complications } \\
\text { True } \\
\text { False } \\
\text { Do not know } \\
\text { No answer }\end{array}$ & $\begin{array}{c}534 \\
2 \\
6 \\
3 \\
\end{array}$ & $\begin{array}{c}97.9 \\
0.4 \\
1.1 \\
0.6 \\
\end{array}$ \\
\hline $\begin{array}{l}\text { In which season(s) there is higher incidence from influenza } \\
\text { (multiple choice) } \\
\text { Spring } \\
\text { Summer } \\
\text { Autumn } \\
\text { Winter } \\
\text { Do not know }\end{array}$ & $\begin{array}{c}141 \\
55 \\
262 \\
463 \\
1\end{array}$ & $\begin{array}{l}26.0 \\
10.1 \\
48.3 \\
85.4 \\
0.2\end{array}$ \\
\hline $\begin{array}{c}\text { Who should be vaccinated against influenza (multiple choice) } \\
\text { People }>65 \text { years } \\
\text { Adults, children }>6 \text { months suffering from chronic diseases } \\
\text { Persons living in medical and social homes, dormitories, etc. } \\
\text { Persons at increased risk of infection- medical staff, army, and police officers, etc. } \\
\text { All the above }\end{array}$ & $\begin{array}{c}42 \\
120 \\
25 \\
83 \\
345\end{array}$ & $\begin{array}{c}7.8 \\
22.3 \\
4.7 \\
15.5 \\
64.2\end{array}$ \\
\hline
\end{tabular}

Plovdiv region. When asked about their education level, $58.3 \%$ of the respondents who claimed to have received the influenza vaccine and $52.2 \%$ of the unvaccinated group had a university degree.

\section{Knowledge}

The respondents showed an overall good knowledge of the characteristics of the influenza infection in terms of contagiousness, possible complications, seasonality, and recommended groups for influenza vaccination (Table 2).

\section{Practices}

In this study, the overall vaccination rate of the respondents was $11 \%$. Further examination of the vaccinated respondents by age groups demonstrated that the relative part of vaccinated people increased with age (Figure 1). We proved an association between the age of the respondents and administration of an influenza vaccine $\left(\chi^{2}=16.687\right.$ $p=0.005)$. Moreover, we found an association between vaccination status and the educational level of the respondents $\left(\chi^{2}=27.002, p=0.00002\right)$. Mostly educated respondents with a university degree stated to be vaccinated with an influenza vaccine in the previous flu season. The higher share of the people who have received the influenza vaccine
$(71.7 \%, \mathrm{n}=43)$ answered that they have received the vaccine from their general physician. No association was established between the financial situation of the respondents and possible influenza vaccination $\left(\chi^{2}=1.88 \mathrm{p}=0.759\right)$.

\section{Attitudes}

Exploring the attitudes of unvaccinated respondents towards the influenza vaccine, $27.6 \%$ of them were uncertain about the effectiveness of the vaccine and almost the same percentage (26.8\%) had the perception that this is not a serious disease. Another reason for non-vaccination was the opposition to vaccination stated by $13.6 \%$ of the participants. However, more than half of the respondents $(51.1 \%)$ were willing to change their attitude towards influenza vaccination and the recommendation and advice from a doctor was the most important for them $(40.8 \%)$.

\section{Discussion}

Influenza vaccination is the primary method for preventing influenza and its severe complications. Among healthy adults, influenza vaccine can prevent $70-90 \%$ of influenza-specific illness. Among the elderly, the vaccine reduces severe illnesses and 


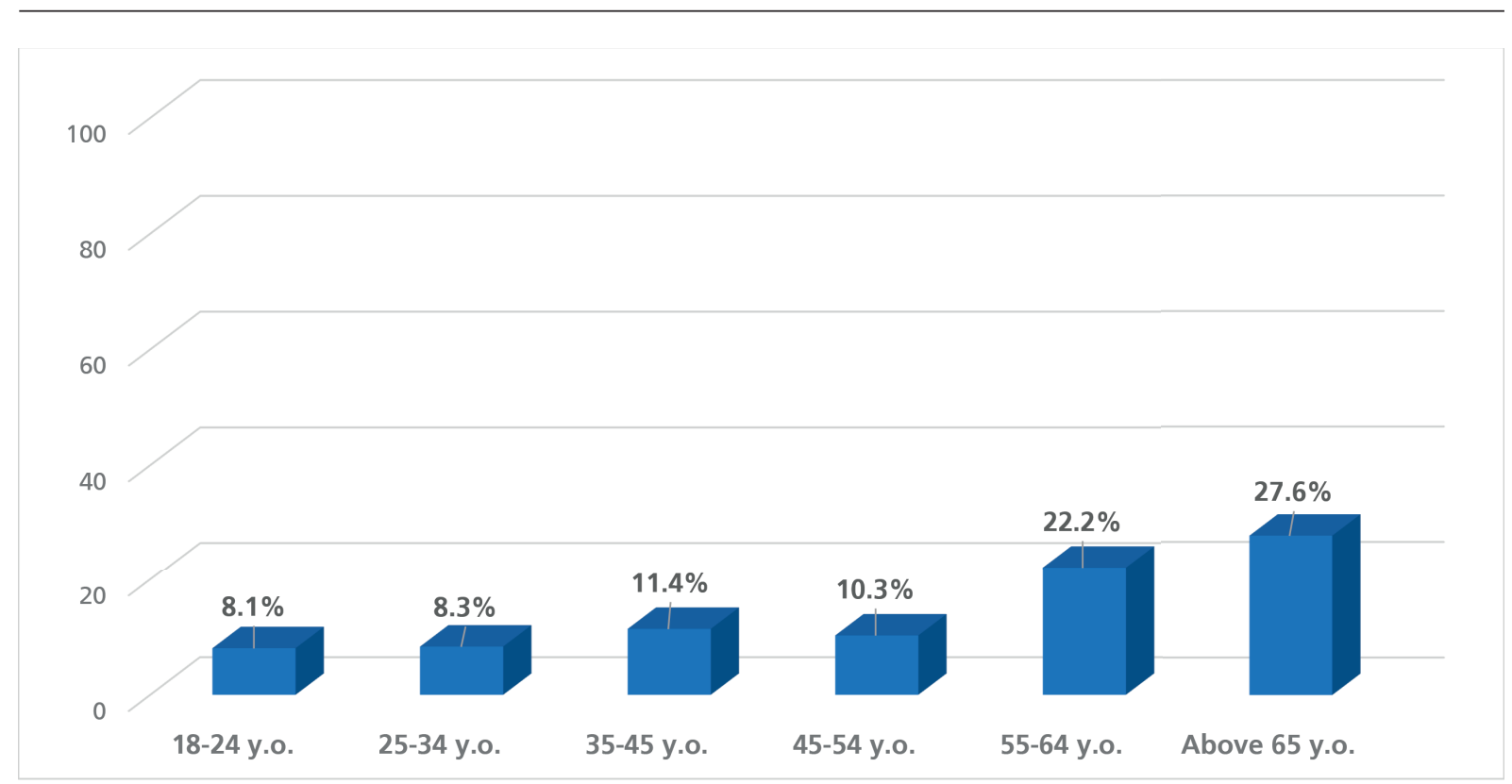

Figure 1. Percentage of vaccinated individuals among different age groups.

Table 3. Attitudes towards the influenza vaccine among the unvaccinated respondents $(n=485)$

\begin{tabular}{ccc}
\hline Characteristics & Frequency $(n)$ & $\%$ \\
The reason you did not vaccinate & & \\
Lack of information & 120 & 25.0 \\
Influenza is not a serious disease & 130 & 26.8 \\
Against vaccines & 66 & 13.6 \\
The vaccine is not effective & 135 & 27.6 \\
No answer & 34 & 7.0 \\
\hline Yes & 248 & 51.1 \\
No & 228 & 47.0 \\
No answer & 9 & 1.9 \\
\hline Additional information from a doctor and explanation about the indications for use & 198 & \\
Information from other sources-TV, internet, newspapers & 59 & 40.8 \\
Recommendation from a friend or relative & 51 & 12.2 \\
Other reasons & 91 & 10.5 \\
No answer & 86 & 18.8 \\
\hline
\end{tabular}

complications by up to $60 \%$ and deaths by $80 \%{ }^{17}$. However, vaccination coverage is still suboptimal in most European countries?

In our study, most of the respondents were aware of some important facts regarding influenza, as the recommendations for vaccination, seasonality, infectivity, and risk groups. Few studies have indicated a weak association between the better knowledge and vaccination. According to two studies, respondents with better knowledge of influenza and vaccination recommendations (OR 1.6-3.3) $)^{18.19}$ and measures to prevent the spread of the virus (OR 1.59-3.06) ${ }^{19}$ were more likely to get vaccinated.

Among the 545 participants, 11\% stated that they have received the influenza vaccine in the previous season. This vaccination rate is higher than that reported by a similar study among the general population, that estimated a $6.7 \%$ vaccination rate $^{20}$ and the national data published from previous seasons ${ }^{7,21}$. The results of our study are significantly lower than the rates reported by other countries such as Germany (40.4\%), France (37.5\%), Spain (56.4\%) and Italy $(48.6 \%)^{7,22}$. Due to this fact, a program to increase the coverage with influenza vaccine was developed in our country for the period 2019-2022 21 . Such programs are essential, considering the present COVID-19 pandemic.

Looking at the age of vaccinated respondents, we found that the coverage increases with age and there was an association between older age and vaccination status $\left(\chi^{2}=16.687 \mathrm{p}=0.005\right)$. This result might be explained by the perceived risk of influenza 
complications, and it corresponds with other studies in European and Asian populations s, $23-25^{\text {. }}$

We found an association between the higher education of the respondents and the possibility for administration of an influenza vaccine $(\chi 2=27.002$, $\mathrm{p}=0.00002$ ), which correlates with studies of other authors ${ }^{26}$. It might seem intuitive that higher education predisposes to a higher vaccination rate, but in the literature this theory is inconsistent. Higher education has been identified as a potential barrier toward vaccination in USA, China, Lebanon, Bangladesh and Israel ${ }^{27-31}$.

Barriers to vaccination included the belief that the vaccine was not effective, and that influenza is not a serious disease that might lead to complications. Similarly, an Australian study found that in the general population the two most stated reasons for not accepting the vaccine were "situation is not serious enough" and "I am not at risk" ${ }^{32}$. The positive view toward the influenza vaccine safety and efficacy has been identified as strongly associated with higher rates of vaccine uptake ${ }^{26}$. The European Centre for Disease Prevention and Control studied the so-called "vaccine hesitancy" phenomenon and determined that the major determinants for opposition to vaccination were concerns about vaccine safety and mistrust of the pharmaceutical industry ${ }^{33-35}$. Future work is needed to increase education, promote awareness, and combat myths of the clinical consequences of influenza in the population and the risk/benefit profile of influenza vaccines.

Physicians play a key role in the public's acceptance of vaccines and their recommendations are an important determinant of vaccination ${ }^{36-39}$. In our study, the highest share of the respondents who haven't been vaccinated in the previous season $(40.8 \%)$ stated that the recommendation and further information from a physician might help them to change their attitude towards influenza vaccine. Other studies also suggested that the recommendation from a physician for regular vaccination was a positive predictor of compliance ${ }^{40,41}$.

To the best of our knowledge, this is one of the few studies to measure the general population's knowledge, attitudes, and practices towards the seasonal influenza vaccine in Bulgaria. However, our study contributes to the effort to further describe the situation in Bulgaria in terms of vaccination rates and provides insightful details that may lead to an increase of the national vaccination rates, not only with influenza vaccine, but with other vaccines, in light of the current COVID-19 pandemic and the strive to reach higher vaccine uptake among the population.

\section{Conclusions}

The present study showed that seasonal influenza vaccine uptake was low in Plovdiv (Bulgaria) and the main driver for vaccine hesitancy was the concern regarding the safety and effectiveness of the vaccine. The recommendation from a physician might help change the negative attitude of some of the respondents. These results emphasize the need to spread public awareness regarding the efficacy and benefits of seasonal influenza vaccination, as well as increasing the involvement of general physicians in carrying out promotional activities on recommended vaccines, such as influenza.

\section{Authors contributions}

V.R conceived the original draft preparation. V.R, A.K., R.R, were responsible for conception and design of the study. M.A, D.A, and S.S were responsible for the collection of data. All authors contributed equally to the present work. All authors contributed to the critical revision of the manuscript for valuable intellectual content. All authors have read and agreed with the final version of the manuscript.

\section{Compliance with Ethics Requirements:}

"The authors declare no conflict of interest regarding this article"

\section{Acknowledgments:}

The article has been funded by the National program for young scientists and post-doctoral students.

\section{References}

1. World Health Organization (WHO). Influenza (seasonal) factsheet N211. http://www.who.int/mediacen tre/ factsheets/fs211/en/. [accessed 01 June 2021].

2. Louie JK, Acosta M, Winter K, et al. Factors associated with death or hospitalization due to pandemic 2009 influenza A(H1N1) infection in California. JAMA. 2009;302(17):18961902.

3. Sambala EZ, Ngcobo N, Machingaidze S, et al. A global review of seasonal influenza vaccine introduction: analysis of the WHO/UNICEF joint reporting form. Expert Rev Vaccines. 2019;18 (8):859-65.

4. World Health Organization. Vaccines against influenza WHO position paper -November 2012. Wkly Epidemiol Rec 2012;47(87):461-76.

5. Influenza Vaccines: WHO Position Paper. Weekly Epidemiological Record. 23 Nov 2012. Available online: http://www.who.int/wer/en/ [accessed 23 June 2021).

6. Prevention and control of influenza with vaccines: Recommendations of the Advisory Committee on Immunization Practices (ACIP), 2010. MMWR Recomm. Rep. 2010;59:1-62. 
7. European Centre for Disease Prevention and Control. Seasonal Influenza Vaccination in Europe. Vaccination Recommendations and Coverage Rates in the EU Member States for Eight Influenza Seasons: 2007-2008 to 20142015. Stockholm; 2017.

8. Freeman D, Waite F, Rosebrock L, et al. Coronavirus conspiracy beliefs, mistrust, and compliance with government guidelines in England. Psychol. Med. 2020, 1-13.

9. Khan YH, Mallhi TH, Alotaibi NH, et al. Threat of COVID-19 vaccine hesitancy in Pakistan: the need for measures to neutralize misleading narratives. Am J Trop Med Hyg. 2020;103:603-604.

10. Peretti-Watel P, Seror V, Cortaredona S, et al. A future vaccination campaign against COVID-19 at risk of vaccine hesitancy and politicisation. Lancet Infect Dis. 2020;20: 769-770.

11. Donovan J. Social-media companies must flatten the curve of misinformation. Nature. 2020. doi: 10.1038/ d41586-020-01107-z

12. McAteer J, Yildirim I, Chahroudi A. The VACCINES act: deciphering vaccine hesitancy in the time of COVID-19. Clin Infect Dis. 2020;71:703-705.

13. Bjorkman I, Sanner MA. The Swedish A(H1N1) vaccination campaign - why did not all Swedes take the vaccination? Health Policy 2013;109(1):63-70.

14. Ward J, Raude J. Understanding influenza vaccination behaviors: a comprehensive sociocultural framework. Expert Rev Vaccines 2014;13(1):17-29.

15. Santibanez TA, Mootrey GT, Euler GL, Janssen AP. Behavior and beliefs about influenza vaccine among adults aged 50-64 years. Am J Health Behav 2010;34(1):77-89.

16. NSI. Statistical data - Urban Audit - FUA of Plovdiv. 2020. https://www.nsi.bg/en/content/18010/basic-page/urban-audit-fua-plovdiv (Accessed 17 April 2021)

17. WHO. Influenza(Seasonal);2009. http://www.who.int/mediacentre/factsheets/fs211/en/ (Accessed 23 June 2021)

18. Lau JT, Au DW, Tsui HY, et al. Prevalence and determinants of influenza vaccination in the Hong Kong Chinese adult population. Am J Infect Control 2012;40(7):e225 -7

19. Takahashi $\mathrm{O}$, Noguchi $Y$, Rahman $\mathrm{M}$ et al. Influence of family on acceptance of influenza vaccination among Japanese patients. Fam Pract 2003;20(2):162-6.

20. Seasonal influenza vaccination: knowledge, attitude and practice in Varna, Bulgaria. Ther Adv Vaccines Immunother. 2019; 7: 2515135519868152.

21. National program for improvement of vaccine prophylaxis of the seasonal influenza 2019-2022 (in Bulgarian) https://www.mh.government.bg/media/filer_public/2019/ 07/29/19rh006pr.pdf

22. Williams WW, Lu P-J, O'Halloran A, et al. Surveillance of vaccination coverage among adult populations-United States, 2015. MMWR Surveill Summ. 2017;66:1-28.

23. Blank PR, Schwenkglenks M, Szucs TD. Vaccination coverage rates in eleven European countries during two consecutive influenza seasons. J Infect 2009;58(6):446 -58.

24. Vaux S, Van Cauteren D, Guthmann JP, et al. Influenza vaccination coverage against seasonal and pandemic influenza and their determinants in France: a cross-sectional survey. BMC Public Health 2011;11:30.

25. Liao QY, Wong WS, Fielding R. Comparison of different risk perception measures in predicting seasonal influenza vaccination among healthy chinese adults in Hong Kong: a prospective longitudinal study. PLoS One 2013;8(7):e68019.

26. Sales IA, Syed W, Almutairi MF, Al Ruthia Y. Public knowledge, attitudes, and practices toward seasonal influenza vaccine in Saudi Arabia: a cross-sectional study. Int J Environ Res Public Health. 2021;18(2):479.

27. Wei F, Mullooly JP, Goodman MJ, et al. Identification and characteristics of vaccine refusers. BMC Pediatr. 2009;9:18.

28. Zhang S, Yin Z, Suraratdecha C, et al. Knowledge, attitudes and practices of caregivers regarding Japanese encephalitis in Shaanxi Province, China. Public Health 2011;125:79-83.

29. Sinno DD, Shoaib H, Musharrafieh UM, Hamadeh GN. Prevalence and predictors of immunization in a health insurance plan in a developing country. Pediatr Int. 2009;51:520525.

30. Rahman M, Obaida-Nasrin S. Factors affecting acceptance of complete immunization coverage of children under five years in rural Bangladesh. Salud Pública México 2010; 52:134-140.

31. Muhsen K, El-Hai RA, Amit-Aharon A, et al. Risk factors of underutilization of childhood immunizations in ultraorthodox Jewish communities in Israel despite high access to health care services. Vaccine 2012;30:2109-2115.

32. Seale H, Heywood AE, McLaws ML, et al. Why do I need it? I am not at risk! Public perceptions towards the pandemic (H1N1) 2009 vaccine. BMC Infect Dis 2009; 10.

33. Karafillakis E, Dinca I, Apfel F, et al. Vaccine hesitancy among healthcare workers in Europe: A qualitative study. Vaccine. 2016;34(41):5013-5020

34. Bellia C, Setbon M, Zylberman P, Flahault A. Healthcare worker compliance with seasonal and pandemic influenza vaccination. Influenza Other Respir Viruses. 2013;7 Suppl 2:97-104.

35. Maltezou HC, Poland GA. Vaccination policies for healthcare workers in Europe. Vaccine. 2014;32(38):4876-4880.

36. Dube E, Gilca V, Sauvageau C, et al. Canadian family physicians' and paediatricians' knowledge, attitudes and practices regarding $\mathrm{A}(\mathrm{H} 1 \mathrm{~N} 1)$ pandemic vaccine. BMC Res Notes. 2010; 3:102.

37. McAnerney JM, Walaza S, Cohen AL, et al. Effectiveness and knowledge, attitudes and practices of seasonal influenza vaccine in primary healthcare settings in South Africa, 2010-2013. Influenza Other Respir Viruses. 2015;9(3):143-150.

38. Shono A, Kondo M. Factors associated with seasonal influenza vaccine uptake among children in Japan. BMC Infect Dis. 2015;15:72.

39. Durando P, Alicino C, Dini G, et al. Determinants of adherence to seasonal influenza vaccination among healthcare workers from an Italian region: results from a cross-sectional study. BMJ Open. 2016;6(5): e10779.

40. Colquhoun AJ, Nicholson KG, Botha JL, Raymond NT. Effectiveness of influenza vaccine in reducing hospital admissions in people with diabetes. Epidemiol Infect. 1997;119(3):335-41.

41. Avelino-Silva VI, Avelino-Silva TJ, Miraglia JL, Miyaji KT, Jacob-Filho W, Lopes MH. Campaign, counseling, and compliance with influenza vaccine among older persons. Clinics (Sao Paulo). 2011;66(12):2031-5. 